\title{
Mineração
}

\section{Adequação da lavra de caulim às diretrizes ambientais}

\section{(Environmental legislation applied to kaolin mining)}

\author{
Simone Picarelli \\ Eng. Agr., Doutoranda - PPGEM - UFRGS - Porto Alegre, RS, Brasil.E-mail: simone.picarelli@ufrgs.br \\ Jair Carlos Koppe \\ Eng. Minas, Professor - PPGEM - UFRGS - Porto Alegre, RS, Brasil.E-mail: jkoppe@ufrgs.br \\ João Felipe Coimbra Leite Costa \\ Eng. Minas, Professor - PPGEM - UFRGS - Porto Alegre, RS, Brasil.E-mail: jfelipe@ufrgs.br \\ Cláudio F. Luft \\ Geólogo, Colorminas - Criciúma,SC,Brasil.E-mail: cláudio@colorminas.com.br
}

\section{Resumo}

A empresa Colorminas Colorifício e Mineração S.A. iniciou suas operações em Pantano Grande-RS antes da década de 80. Passivos ambientais foram gerados, principalmente nas áreas exauridas pela lavra.

Esse trabalho apresenta o resultado dos procedimentos de recuperação de três minas de caulim da empresa. Nesse contexto, foi criado o projeto "Colorminas: mineração com responsabilidade”.

A metodologia adotada e os resultados obtidos são apresentados, conjuntamente ao investimento para implantação e execução do projeto. Atualmente todas as áreas estão regularizadas, os passivos ambientais em processo de recuperação e a lavra é executada paralela aos procedimentos de reabilitação das áreas mineradas.

Palavras-chave: Recuperação de áreas degradadas, investimento ambiental, mineração.

\section{Abstract}

Kaolin mining has been carried out by the Colorminas Company in Pantano Grande-RS since the 80 's. As environmental legislation was not applied, land reclamation was not performed.

This paper presents land reclamation for the kaolin mines and the basis of the project "Colorminas: mining with responsibility".

A detailed description of the reclamation procedures is presented, together with its costs and the investment in the project.

Keywords: Land rehabilitation, mining, cost operation. 


\section{Introdução}

A empresa Colorminas Colorifício e Mineração S.A., tem sede em Içara - SC. A Colorminas opera em Pantano Grande/RS desde 1977, extraindo cerca de 15 mil toneladas mensais de matéria-prima para a indústria cerâmica. Nesse período, as normatizações ambientais não tinham os moldes atuais. Essa situação permitiu a geração de passivos ambientais, principalmente nas áreas exauridas dos depósitos de caulim e argila/areia anortosítica. Com a aplicação das novas diretrizes ambientais e a necessidade de licenciamento, a empresa reformulou sua estratégia de mineração. Esse trabalho apresenta o resultado da recuperação de três áreas mineradas, a readequação dos procedimentos operacionais e o investimento realizado. Essa nova disposição influenciou na adoção de medidas ambientais no seu planejamento de lavra. Os principais objetivos foram sanear plenamente seus passivos e, ao final da operação, em cada frente de lavra, recuperar as áreas em concordância com a legislação ambiental vigente. Nesse contexto, foi criado o projeto "Colorminas: mineração com responsabilidade”.
Em um ano e meio de atuação do projeto, todas as áreas foram regularizadas no órgão fiscalizador, as áreas exauridas estão em estágio avançado de recuperação e novos procedimentos foram adotados nas operações mineiras.

\section{Localização e aspectos geológicos}

A Colorminas possui três frentes de lavra em operação em Pantano Grande/ RS, sendo elas a área 1, área 2 e a área 3, conforme a Figura 1.

A região de Pantano Grande, no Rio Grande do Sul, é a única da região sul do Brasil onde ocorrem jazimentos de rochas anortosíticas. A ação do intemperismo sobre o maciço anortosítico, na faixa superior, através dos fenômenos de oxidação, hidrólise e dessilicatização, deu origem às camadas de material argiloso e caulins. Na faixa inferior, o predomínio da desagregação mecânica da rocha formou bolsões e lentes de material arenoargiloso, por meio do processo de arenização. O material extraído na área é de fundamental importância na produção de revestimentos cerâmicos pelo processo de monoqueima porosa, conferindo à massa cerâmica boa estabilidade dimensional durante a queima, contribuindo, ainda, com sua cor de queima branca. A geologia local é apresentada por duas unidades litológicas, o Anortosito Capivarita e a Suíte Granítica Encruzilhada do Sul ou Granito Encruzilhada.

\section{Aspectos econômicos}

Foram considerados como investimento ambiental todos os procedimentos adotados para lavra e recuperação de áreas previamente lavradas, incluindo-se os custos de execução da legislação ambiental nos procedimentos de lavra. Consideramos como custo de execução da legislação ambiental todo procedimento necessário para a regulamentação das áreas: taxas para obtenção das licenças ambientais (CONAMA n ${ }^{\circ} 237$ ), custo para a elaboração dos relatórios, técnicos responsáveis pela execução das medidas ambientais que estão inseridos no grupo “administrativos”, explicitado a seguir. Os passivos gerados pela empresa e por terceiros de forma irregular foram assumidos e recuperados pela

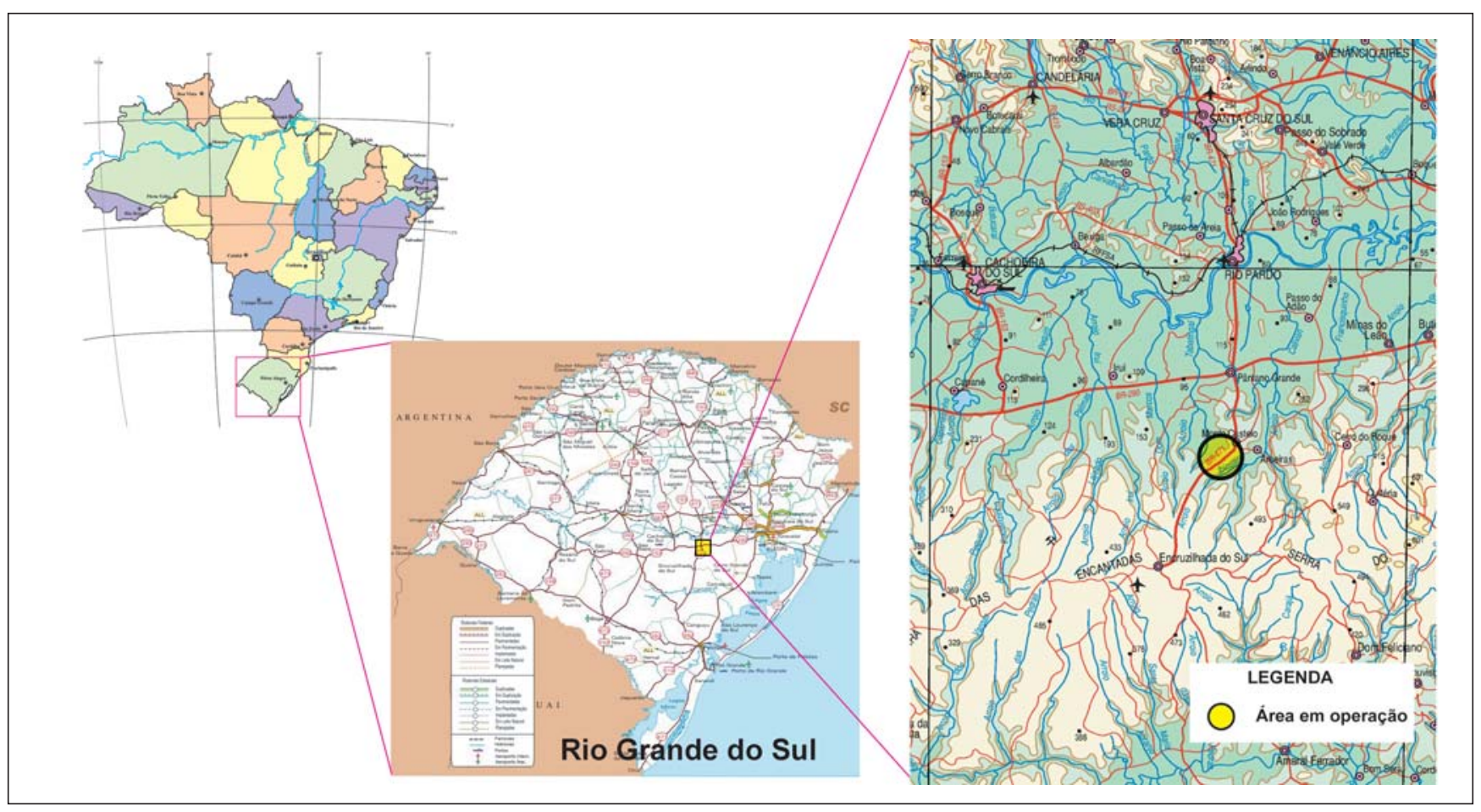

Figura 1 - Localização das áreas 1, 2 e 3 no Rio Grande do Sul. 
empresa no primeiro ano de atuação do projeto. Os recursos disponibilizados foram considerados como custo de investimento, para início do projeto, e foram posteriormente somados aos custos operacionais vinculados à produção. Presentemente os custos operacionais do projeto continuam sendo avaliados e armazenados, visando a fazer uma nova avaliação do investimento na operação nos períodos subseqüentes. $\mathrm{O}$ valor total investido (designado de "investimento ambiental”) na implantação e execução do projeto foi dividido em 5 grupos: (i) “utilização de equipamentos”, (ii) “administrativos”, (iii) investimentos em processos de revegetação e monitoramento, (iv) benfeitorias e (v) outros.

No grupo de investimentos "administrativos" foram incluídas as horas dos técnicos empregadas na elaboração e desenvolvimento do projeto, as taxas das licenças ambientais, o transporte, a hospedagem, a alimentação e os programas de educação ambiental. O grupo "administrativos” representou 29\% do total investido. No grupo "revegetação e monitoramento”, estão diretamente envolvidos os custos de aquisição de sementes, adubação, mão-de-obra para o plantio, mudas de árvores e análises de água, representando $7 \%$ do investimento. No grupo "benfeitorias”, estão incluídos os valores empregados na construção de almoxarifados, pisos impermeáveis, cercas para as áreas recuperadas. Nesse grupo, a depreciação foi estimada em cinco anos. O total investido no grupo "benfeitorias” foi de $2 \%$. No grupo chamado de "outros", foram inseridos as demais atividades e imprevistos representando um valor aproximado de $5 \%$ do valor total.

A utilização de equipamentos foi calculada a partir de horas-máquina. Foram incluídas as horas-máquinas utilizadas para a conformação de bancadas, construção das bacias de sedimentação, limpeza das bacias, movimentação do solo orgânico para as áreas em recuperação e implantação do sistema de drenagem, entre outros. Foi considerado o custo operacional e o custo improdutivo (depreciação, juros, manutenção e operação) (Dias, 2001). O investimento em termos de utilização de equipamentos foi de 57\% do valor total aplicado na implantação e execução do projeto.

\section{Procedimentos de readequação de lavra e recuperação de passivos}

A primeira etapa do trabalho foi readequar a topografia das frentes de lavra. Além das bancadas na frente de lavra, foi implantado um sistema de drenagem em contorno, evitando, assim, que a água pluvial causasse a ruptura dos taludes e o desenvolvimento de focos de erosão. Toda a água é conduzida para as bacias de sedimentação (Figura 2) antes de deixar a área.

Concomitante ao decapeamento, o material estéril e o solo orgânico passaram a ser estocados separadamente. O solo orgânico fica estocado ao lado da próxima área a receber os procedimentos de readequação topográfica e revegetação, ou seja, na frente exaurida. $\mathrm{O}$ material estéril é depositado na parte posterior ao avanço da lavra e distribuído de forma a readequar a topografia. Nas pilhas de estéril, assim que a deposição do material é finalizada, são construídas bancadas. As bancadas contribuem no controle da erosão, facilitando o estabelecimento da vegetação de cobertura. $\mathrm{O}$ dimensionamento adequado das bancadas é fundamental para evitar movimentos de blocos, rastejamentos, transporte de material particulado e assoreamentos. Os procedimentos de recuperação são diretamente afetados quando esses parâmetros não são adequadamente seguidos. Imediatamente após a conformação final, o solo e os resíduos orgânicos são redistribuídos e é iniciado o procedimento de semeadura das espécies de cobertura de solo, visando ao estancamento do processo erosivo e ao início da sucessão natural (Figuras 3 e 4).

Um dos passivos herdados foi um depósito de estéril em pilhas não conformadas. Além dos focos de erosão e transporte de sedimentos, caracterizava- se como um impacto visual negativo. $\mathrm{O}$ depósito foi todo remodelado e foram construídas bancadas. A reconformação topográfica de passivos antigos responderam pelo maior número de horas-máquinas que compõem o grupo "utilização de equipamentos”. Foram necessários três ciclos de plantio para o estancamento da erosão e fixação das plantas de cobertura. A instabilidade do solo, a falta de estrutura e porosidade, típico de solos construídos (Kampf et al., 2000), tornam esses pontos os mais difíceis e demorados para serem recuperados.

Quanto mais efetivos e paralelos ao processo de lavra forem os procedimentos de implantação da cobertura vegetal, menores os impactos de assoreamento e contaminação dos recursos hídricos nas adjacências do empreendimento.

Devido ao clima no Rio Grande do Sul, foi necessária a divisão da implantação de cobertura de solo em duas etapas: os plantios estivais e hibernais. A primeira etapa do procedimento de revegetação das áreas corresponde à introdução de espécies de cobertura de solo, com gramíneas e leguminosas pioneiras, de hábitos rasteiros e com maior possibilidade de cobertura eficiente do solo (Monegat, 1991). Salienta-se a falta de opções, principalmente, de espécies nativas a serem usadas nessa etapa. São utilizadas espécies exóticas, buscandose características como rusticidade e adaptação ao clima local (Picarelli et al., 2002). Na adubação, foram utilizados adubos químicos (NPK) e uréia em todas as áreas semeadas.

Nas áreas de preservação permanente, utilizou-se a técnica baseada no modelo sucessional (CETESB, 1992), visando a acelerar o processo de sucessão natural, que ocorreria normalmente, porém, de maneira lenta, variando de acordo com o grau de degradação da área. Assim, em áreas de proteção, 30-40m ao longo dos cursos d'água, foram plantadas mudas de árvores nativas pioneiras, heliófitas e rústicas, capazes de se desenvolver em situações adversas (Reitz et al., 1983). Foram selecionadas espécies que são atrativas à fauna local. 
Todas as minas foram cercadas, com o objetivo de não permitir a entrada de pessoas estranhas e animais. Foram colocadas placas de sinalização e identificação dos responsáveis pela lavra. Um dos problemas enfrentados tem sido o roubo de ferramentas e o pastejo indevido nas áreas em recuperação.

As análises da água nas minas são realizadas quadrimensalmente, em 22 pontos de coleta. São elaborados relatórios com os resultados analíticos, que são, posteriormente, apresentados ao órgão ambiental estadual. Os resultados analíticos de cada ponto amostral são comparados aos resultados de um ponto de referência. Assim, a análise dos dados se baseia na qualidade da água que entra na área e na qualidade da água ao sair da área da mina (Figura 5). São realizadas análises dos seguintes parâmetros: sólidos totais, sódio, potássio, cálcio, dureza, alcalinidade, turbidez, pH e cor.

As bacias de sedimentação são limpas, em média, 4 vezes por ano e têm sido eficientes na retenção dos sólidos carreados pelas águas pluviais. Em torno de 600 toneladas de material são retiradas das bacias a cada procedimento de limpeza. $\mathrm{O}$ material resultante da limpeza das bacias é disposto nas áreas que estão em processo de adequação topográfica. Como as áreas no entorno das minas são utilizadas para a agropecuária ou são mineradas por outras empresas, em algumas coletas, a qualidade da água que deixa as áreas é melhor do que nos pontos de referência.

Nas três áreas de lavra, foram construídos pisos impermeáveis com caixas separadoras de água e óleo. A manutenção das máquinas e a lavagem dos veículos são realizadas nos pisos impermeáveis. Juntos aos pisos impermeáveis foram construídos os almoxarifados, com água canalizada.

No projeto "Colorminas: mineração com responsabilidade” foi incluída, também, a parte social. Procurando manter um bom relacionamento com a comunidade e construindo uma nova imagem da mineração, a empresa tem realizado atividades com as escolas municipais.

O foco principal das palestras tem sido a relação da atividade de mineração com o cotidiano, salientando a presença nos produtos manufaturados de matérias primas da atividade, principalmente dos produtos explotados na região. Salientase o desconhecimento por parte da comunidade da atividade de mineração e, principalmente, qual é a utilização das matérias-primas explotadas. A empresa é apresentada, detalhandose o seu processo de produção e quais produtos finais são gerados com o material minerado pela Colorminas. A segunda etapa da atividade é a apresentação dos procedimentos de recuperação. A região tem um dos maiores passivos ambientais do estado, gerado por anos de mineração irresponsável. Após a apresentação dos procedimentos de recuperação adotados pela empresa, as crianças visitam as minas e são convidadas a participarem do plantio de mudas nativas, recebendo de presente alguns exemplares.

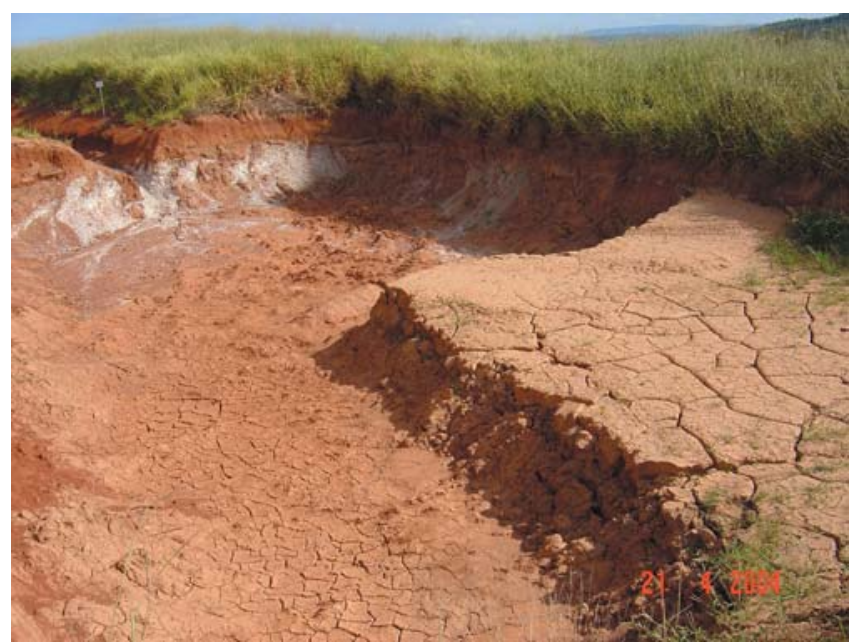

Figura 2 - Bacia de sedimentação parcialmente limpa em abril de 2004. Salientam-se a grande quantidade de material depositado e a revegetação ao longo dos talvegues.

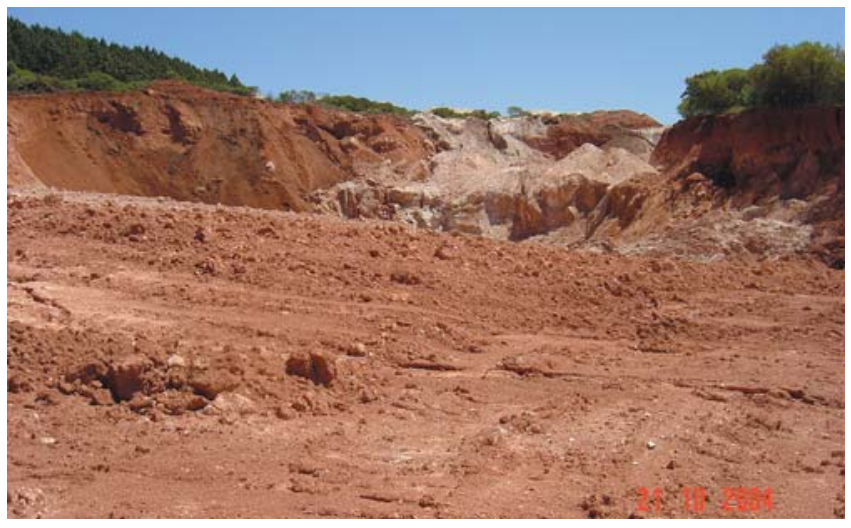

Figura 3 - Frente exaurida, início da recomposição da topografia em outubro de 2004.

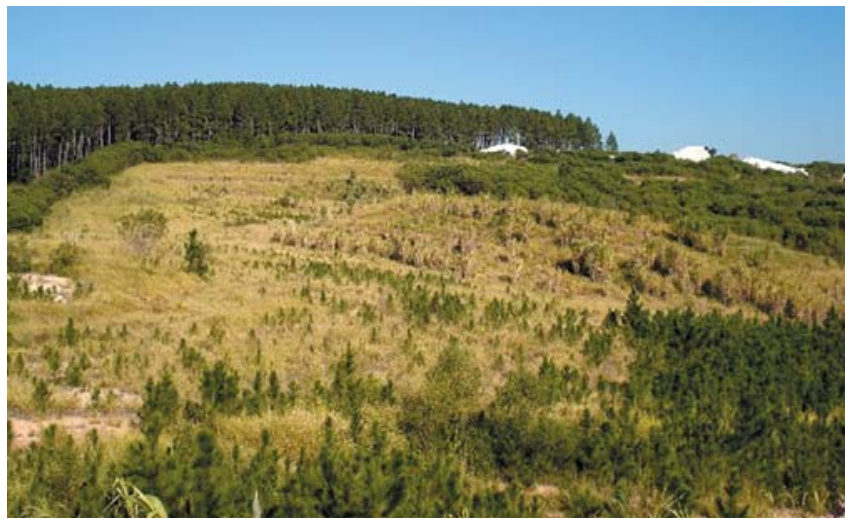

Figura 4 - Distribuição de solo orgânico, serrapilheira e semeadura de espécies de cobertura. Mesma área da Figura 3, em junho de 2007.

\section{Discussões}

O valor total investido na implantação e operação do projeto "Colorminas: mineração com responsabilidade", nesse primeiro ano, contabilizando-se a recuperação dos passivos já existentes, as modificações das operações mineiras, 
as atividades de educação ambiental e monitoramentos, incidiu em $13,5 \%$ do custo de produção das três áreas mineradas. Considerando-se a receita líquida como o valor da venda da produção de minério descontados os impostos, os valores investidos foram de, aproximadamente, $7 \%$. Em relação à receita bruta, ou seja, valor de venda em relação à produção total, o "investimento ambiental" foi de $6 \%$. O valor total aplicado incidiu em um custo de US\$0,50/t de minério produzido.

O projeto de fechamento de uma mina deve basear em exemplos reais de outras empresas, sempre considerando que os procedimentos ambientais devem ser iniciados durante a implantação e continuados após o término das operações de lavra, evitando-se que, ao fim da lavra, quando não há aporte de receitas, o capital destinado pela empresa para esse fim seja insuficiente (Oliveira Júnior et al., 2002).

Oliveira Neto (1999), avaliando três empreendimentos de portes diferentes, verificou que os custos ambientais não crescem proporcionalmente à produção, o que contraria o conceito que, quanto mais se produz, maior o impacto, sendo que o custo ambiental deveria variar nas mesmas proporções. Concluiu, assim, que, para as pequenas minerações, os custos ambientais incidem proporcionalmente com maior intensidade nos custos de produção do que para as grandes empresas. As dificuldades financeiras para a regularização levam à clandestinidade e à irregularidade. Um aspecto importante a ser destacado é o fato de que, aproximadamente, 70\% (DNPM/DIRIN, 2002) das empresas do país são de pequeno porte e representam um impacto ambiental muito maior do que o conjunto das grandes empresas, normalmente com projetos ambientais bem estruturados e consolidados.

Os impostos, também, oneram, sobremaneira, as pequenas e médias empresas. A empresa, para a venda, recolhe os seguintes impostos, COFINS (contribuição para financiamento da seguridade social), PIS (programa de integração social), CEFEM (compensação financeira pela lavra de recursos minerais) e
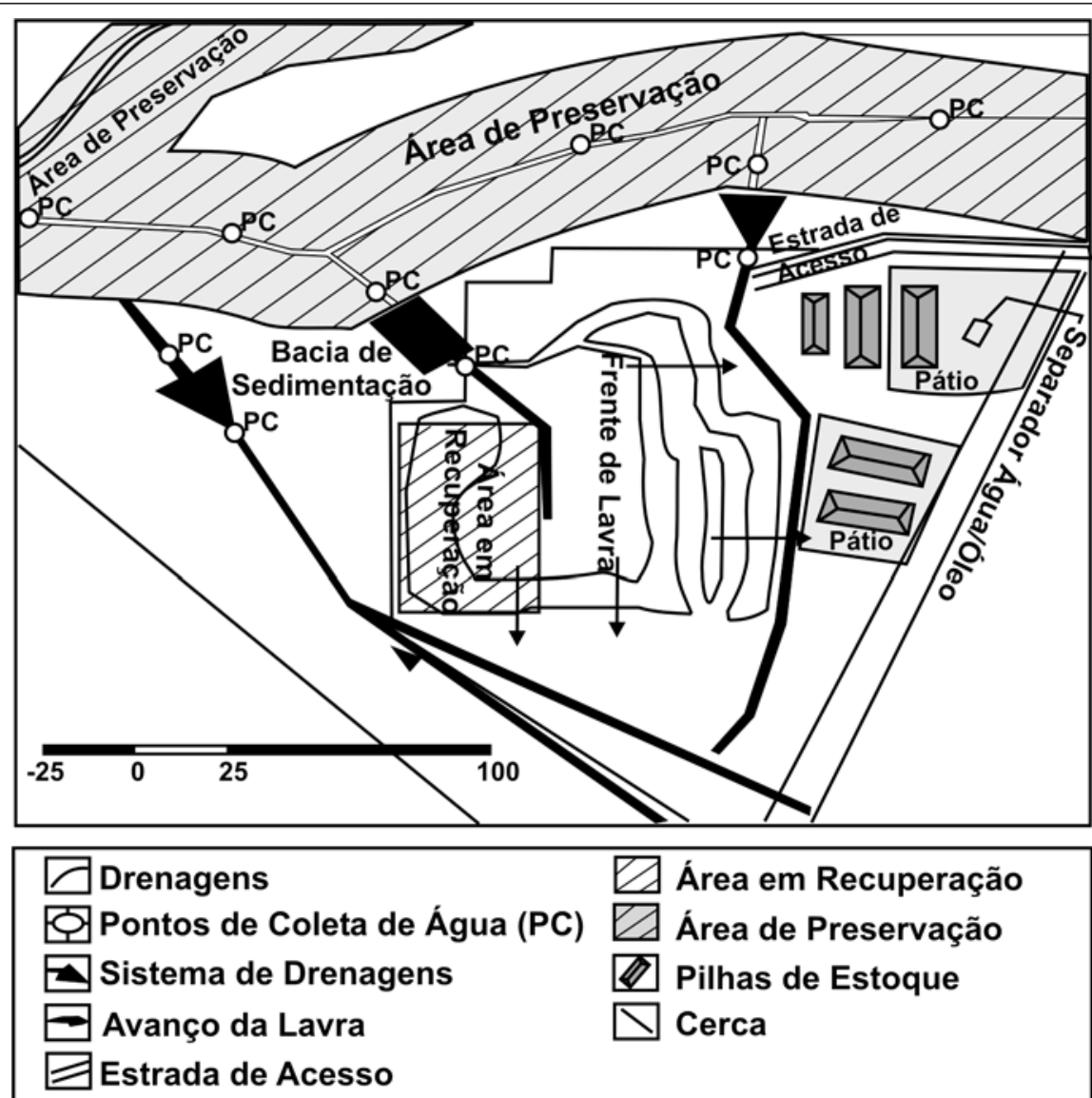

Figura 5 - Desenho esquemático da mina, salientando o sistema de drenagem e os pontos de coleta das amostras de água e a dinâmica da recuperação, onde as áreas em recuperação são a parte posterior ao avanço da lavra.

ICMS (impostos sobre circulação de mercadorias), que oneram em, aproximadamente, $18 \%$ a produção. Assim, somando-se o investimento ambiental desse primeiro ano de projeto e os impostos pagos pela empresa, o percentual incidente sobre a receita bruta é de $24 \%$.

\section{Conclusões}

Os procedimentos adotados para a recuperação das áreas degradadas foram satisfatórios. Todas as frentes exauridas estão em processo de recuperação e todas as áreas regularizadas.

A incorporação dos procedimentos ambientais ao processo de lavra mostrouse eficiente. O principal resultado foi a diminuição de horas-máquina nos procedimentos de recuperação. A separação e a disposição do estéril e do solo orgânico, em locais adequados, permitem o andamento paralelo da lavra e recuperação.
Os principais objetivos do projeto estão sendo atingidos, como o saneamento dos passivos e a minimização na geração de novos, permitindo, assim, que a área esteja em estágio avançado de recuperação, quando for exaurido o depósito mineral, minimizando o investimento necessário para o seu fechamento.

Hoje as minas têm uma produção de minério superior, quando se faz uma comparação com períodos anteriores, estão mais bem organizadas e os dias não produtivos foram diminuídos.

O treinamento, a conscientização e o conhecimento, por parte dos operadores, em relação aos procedimentos adotados na mineração, foram fundamentais para o bom andamento do processo. A mudança no procedimento da empresa partiu da parte administrativa, sendo que toda a equipe de trabalho teve suporte para que as medidas necessárias fossem adotadas, o que influ- 
enciou, sobremaneira, o trabalho dos técnicos e os resultados alcançados. A empresa foi vencedora do prêmio "Expressão Ecologia” no ano de 2004, na categoria recuperação de áreas degradadas com esse projeto.

\section{Agradecimentos}

À Colorminas Colorifício e Mineração S/A, ao Laboratório de Pesquisa Mineral (LPM) da Universidade Federal do Rio Grande do Sul, à CAPES e ao CNPQ.

\section{Referências} bibliográficas

CETESB. Diretrizes para revegetação de áreas degradadas por extração de areia. Jacareí, SP: CETESB, 1992. 68p.
CONAMA. Resolução Conama n²37 de 19 de dezembro de 1997.

DIAS, P.R.V. Engenharia de custos - uma metodologia de orçamentação para obras civis. 3ed. São Paulo: Impressão Hoffmann Gráfica e Editora, 2001. 187p.

DNPM/DIRIN. XIV Universo da mineração brasileira. Minério e Minerales, Ano 21, ed. 265, julho/agosto, p.10-19, 2002.

KAMPF, N. et alii. Solos construídos em áreas de mineração da bacia carbonífera. In: CALESSO, E.T. (ed.). Carvão e Meio Ambiente. Porto Alegre: Ed. Universidade UFRGS, 2000. p. 596-640. 1006p.

MONEGAT, C.E. Plantas de Cobertura de Solo. Curitiba: Ed. Autor, 1991. 336p.

OLIVEIRA JÚNIOR, J.B., SANCHEZ, L.E. Deactivation of mining enterprise analyses of the closure plan of mine at fazenda Maria Preta-Brazil. In: INTERNATIONAL SYMPOSIUM ON ENVIRONMENTAL ISSUE AND WASTE MANAGEMENT IN ENERGY AND MINERAL PRODUCTION (SWEMP),7. Anais..., Cagliari, 2002. p.595601.

OLIVEIRA NETO, R. Avaliação do sistema de licenciamento ambiental vigente para a mineração: uma nova proposta de metodologia e procedimentos. PPGEM-UFRGS, 1999. 74p. (Dissertação de mestrado).

PICARELLI, S., KOPPE, J.C., COSTA, J.F. C.L., BUGIN, A. Modelo de revegetação para recuperação e adequação de áreas degradadas pela lavra na Pedreira Santa Tecla - RS. In: CONGRESSO BRASILEIRO DE MINA À CÉU ABERTO, 2. Anais... Belo Horizonte, 2002. (Em Cd, Trabalho 58).

REITZ, R. et alii. Projeto madeira do Rio Grande do Sul. Itajaí: Imprensa Oficial do Estado de Santa Catarina, 1983. 525p.

Artigo recebido em 30/03/2006 e aprovado em 01/12/2007.

\section{Você não vai esconder seu trabalho de anos de pesquisas numa revista que nunca se sabe quando vai ser publicada, ou que ninguém lê... Vai?}

\section{Conheça e \\ Publique-o na REM \\ 72 anos divulgando ciência.}

*****

\section{www.rem.com.br}

